\title{
Perinatal and Maternal Outcomes in Two Groups of Normal and At the Risk of Borderline Oligohydramnios in Late Preterm Pregnancy
}

\author{
Saddiqa Hassan ${ }^{1}$, Sana Ali ${ }^{1}$, Sajid Hussain Sherazi ${ }^{2}$ \\ ${ }^{1}$ Department of Gynae \& Obstetrics, Niazi Medical and Dental College Sargodha, Pakistan \\ ${ }^{2}$ Department of Paediatrics, Niazi Medical and Dental College Sargodha, Pakistan
}

\author{
Article Information \\ Received: 15 February 2020 \\ Revised version received: 14 march 2020 \\ Accepted: 17 March 2020 \\ Published: 29 March 2020 \\ Cite this article as: \\ S. Hassan et al. (2020) Int. J. Appl. Sci. Biotechnol. Vol \\ 8(1): 29-32. DOI: $\underline{10.3126 / i j a s b t . v 8 i 1.27809}$

\section{*Corresponding author} \\ Saddiqa Hassan, \\ Department of Gynae \& Obstetrics, Niazi Medical and \\ Dental College Sargodha, Pakistan \\ Email: doctorsaddiqa@gmail.com \\ Peer reviewed under authority of IJASBT \\ (C) 2020 International Journal of Applied Sciences and \\ Biotechnology

\section{OPEN $O$ ACCESS}

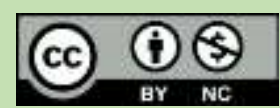 \\ This is an open access article $\&$ it is licensed under a Creative \\ Commons Attribution Non-Commercial 4.0 International \\ (https://creativecommons.org/licenses/by-nc/4.0/)
}

\begin{abstract}
Background: Pregnancy outcomes of a borderline oligohydramnios versus normal relatively comes to be slightly increasing meconium-stained fluid, low Apgar scores and hyper bilirubinemia on follow up as perinatal outcomes and increased risk of $\mathrm{C}$ section as maternal outcome. There is currently insufficient evidence to recommend additional perinatal and maternal testing based on a borderline oligohydramnios. Clinical determination is considered in evaluating meconium-stained fluid, low Apgar scores and hyper bilirubinemia. Objective: The purpose of this study is to determine the adverse perinatal and maternal outcomes in uncomplicated late preterm pregnancies with borderline oligohydramnios. Setting: A total of 38 patients were studied, 19 were with normal AFI and 19 patients were of borderline AFI. Patients with normal AFI were referred as Group 1 and the other as Group 2. This study was conducted at Niazi Medical and Dental College, Sargodha. Population: Pregnant women with normal AFI at term and borderline patients with late preterm pregnancy and borderline oligohydramnios. Methods: This descriptive study was conducted at Niazi Medical and Dental College, Sargodha. This study comprised of 38 patients with normal AFI and border line AFI. Data of 19 patients with normal AFI and 19 patients with border line AFI was collected. The Inclusion Criteria was 19 singleton pregnancies of $36+6$ weeks, with AFI $\leq 8 \mathrm{~cm}$ and 19 singleton pregnancy $37+$ weeks with upto $24 \mathrm{~cm}$ AFI. In both groups, Maternal and perinatal outcomes were assessed. The results of both groups were compared in the end. Conclusion: The results of this study indicated that borderline AFI was not a risk for adverse perinatal and maternal outcomes in uncomplicated, late preterm pregnancies.
\end{abstract}

Keywords: caesarean rate; meconium staining; perinatal outcomes; jaundice

\section{Introduction}

Amniotic fluid is one of the determining factors of fetal wellbeing during pregnancy and it is essential for normal fetal growth and development. Decreased amniotic fluid is often associated with chronic uteroplacental insufficiency, preterm premature membrane rupture, preeclampsia, maternal vascular diseases, and fetal oliguria in the third trimester. Oligohydramnios or a reduced volume of amniotic fluid poses a challenge in obstetric management, particularly when it is diagnosed before term. It is one of the major challenges for antenatal fetal surveillance and induction of labour. The incidence of oligohydramnios in the literature varies from less than $0.5 \%$ (Hill et al., 1983) to above 5\% (Mercer et al., 1984), depending on the study population and definition of oligohydramnios. Oligohydramnios, often due to impaired placental function, has been associated with an increased risk of caesarean delivery for fetal distress, as well as low Apgar score, meconium and perinatal mortality and morbidity (Chauhan 
et al., 1999). The present study aimed to evaluate the adverse fetal outcomes in uncomplicated late preterm pregnancies with isolated borderline oligohydramnios. The purpose of this investigation was to determine the relationship between oligohydramnios and adverse maternal and neonatal outcomes. Although several previous studies have evaluated borderline AFI and adverse perinatal outcomes, it is difficult to compare these studies, due to their different inclusion and exclusion criteria, different gestational weeks, and different definitions of borderline AFI (Magann et al., 2011). Newborns delivered by cesarian section (CS) can be assessed clinically using the Apgar scores to evaluate the health of newborn and assess the effects of obstetric anesthesia on newborns at birth (Berchicci et al., 2015). The test is simple and repeatable method to assess the health of newborn immediately after delivery and to determine any immediate need for extra emergency care (Berglund et al., 2010). Five factors are used to evaluate the baby's condition and each factor is scored on a scale of 0 to 7 , with 7 being the best score for each: the scoring system is an accepted tool for assessing the vitality of newborns. The score is based on measures of heart rate, respiratory effort, skin color, muscle tone, and reflex irritability (Iliodromiti et al., 2014). The purpose of this study is to determine the adverse perinatal and maternal outcomes in uncomplicated late preterm pregnancies with borderline oligohydramnios.

\section{Methods}

This descriptive study was conducted at Niazi Medical and Dental College, Sargodha. This study comprised of 38 patients with normal AFI and border line AFI. Data of 19 patients with normal AFI and 19 patients with border line AFI was collected. The Inclusion Criteria was 19 singleton pregnancies of $36+6$ weeks, with AFI $\leq 8 \mathrm{~cm}$ and 19 singleton pregnancy $37+$ weeks with upto $24 \mathrm{~cm}$ AFI. In both groups, Maternal and perinatal outcomes were assessed. The results of both groups were compared in the end.

\section{Results and Discussion}

Data of 19 patients at $36+6$ weeks with AFI $\leq 8 \mathrm{~cm}$ and 19 singleton pregnancy $37+$ weeks with upto $24 \mathrm{~cm}$ AFI was collected at Niazi Medical and Dental Collage Sargodha. Patients were collected as two groups. Group 1: Patients with normal AFI. 19 patients were included in this group at term pregnancy. Maternal and perinatal outcomes were noted in this group and compared with another group of 19 patients of late preterm birth with borderline AFI. Caesarean section rate was included in maternal outcome and meconium staining, jaundice and APGAR scores were the perinatal outcomes. In group 1, previous caesarean section rate was 4 . Meconium staining was 6 , jaundice was 5 and APGAR score with $<7$ was 4 . Comparing the results of both groups, it was noticed that there wasn't a big difference between patients of both groups. There was a slight change in their result. In group 1 (Table 1), Caesarean rate was $4(21.1 \%$ ) whereas in group 2 (Table 2), caesarean rate came out to be $5(26.3 \%)$. Coming on perinatal outcomes, in group 1, APGAR score was $<7$ in 4 patients $(21.1 \%)$ (Table 3 ) and in group 2, 5(26.3\%) patients had APGAR scores $<7$ (Table 4). Noticing the effect of meconium staining, it was observed that group 1 had $6(31.6 \%)$ patients with fetal meconium staining (Table 5) and in group 2, 7(36.8\%) patients were presented with fetal meconium staining (Table 6). If we observe the results of jaundice in both groups, group 1 had 5(26.3\%) and group 2 had, 6 patients had fetal jaundice on follow-up. After combining the results of both groups, it was noticed that there's a slight difference between maternal and perinatal outcomes of both groups. Thus, normal AFI and borderline AFI doesn't affect the maternal or perinatal outcomes (Fig. $1)$.

Table 1: Frequency of Caesarean section as maternal outcome in Group 1 of patients with Oligohydramnios

\begin{tabular}{|l|l|l|}
\hline Caesarean section rate & Frequency & Percent \\
\hline No & 15 & 78.9 \\
\hline Yes & 4 & 21.1 \\
\hline Total & 19 & 100.0 \\
\hline
\end{tabular}

Table 2: Frequency of Caesarean section as maternal outcome in Group 2 of patients with boarder line AFI

\begin{tabular}{|l|l|l|}
\hline Caesarean section rate & Frequency & Percent \\
\hline No & 14 & 73.6 \\
\hline Yes & 5 & 26.3 \\
\hline Total & 19 & 100.0 \\
\hline
\end{tabular}

Table 3: Frequency of APGAR score as perinatal outcome in Group 1 of patients with Oligohydramnios

\begin{tabular}{|l|l|l|}
\hline APGAR score & Frequency & Percent \\
\hline$<7$ & 4 & 21.1 \\
\hline$>7$ & 15 & 78.9 \\
\hline Total & 19 & 100.0 \\
\hline
\end{tabular}

Table 4: Frequency of APGAR score as perinatal outcome in Group 2 of patients with boarder line AFI

\begin{tabular}{|l|l|l|}
\hline APGAR score & Frequency & Percent \\
\hline$<7$ & 5 & 26.3 \\
\hline$>7$ & 14 & 73.7 \\
\hline Total & 19 & 100.0 \\
\hline
\end{tabular}


Table 5: Frequency of Meconium staining as perinatal outcome in Group 1st of patients with Oligohydramnios

\begin{tabular}{|l|l|l|}
\hline Meconium staining & Frequency & Percent \\
\hline No & 13 & 68.4 \\
\hline Yes & 6 & 31.6 \\
\hline Total & 19 & 100.0 \\
\hline
\end{tabular}

Table 6: Frequency of Meconium staining as perinatal outcome in Group 2nd of patients with boarder line AFI

\begin{tabular}{|l|l|l|}
\hline Meconium staining & Frequency & Percent \\
\hline No & 12 & 63.2 \\
\hline Yes & 7 & 36.8 \\
\hline Total & 19 & 100.0 \\
\hline
\end{tabular}

Table 7: Frequency of Jaundice as perinatal outcome in Group 1st of patients with Oligohydramnios

\begin{tabular}{|l|l|l|}
\hline Jaundice & Frequency & Percent \\
\hline No & 14 & 73.7 \\
\hline Yes & 5 & 26.3 \\
\hline Total & 19 & 100.0 \\
\hline
\end{tabular}

Table 8: Frequency of Jaundice as perinatal outcome in 2nd Group of patients with borderline AFI

\begin{tabular}{|l|l|l|}
\hline Jaundice & Frequency & Percent \\
\hline No & 13 & 68.42 \\
\hline Yes & 6 & 31.5 \\
\hline Total & 19 & 100.0 \\
\hline
\end{tabular}

APGAR score with normal AFI

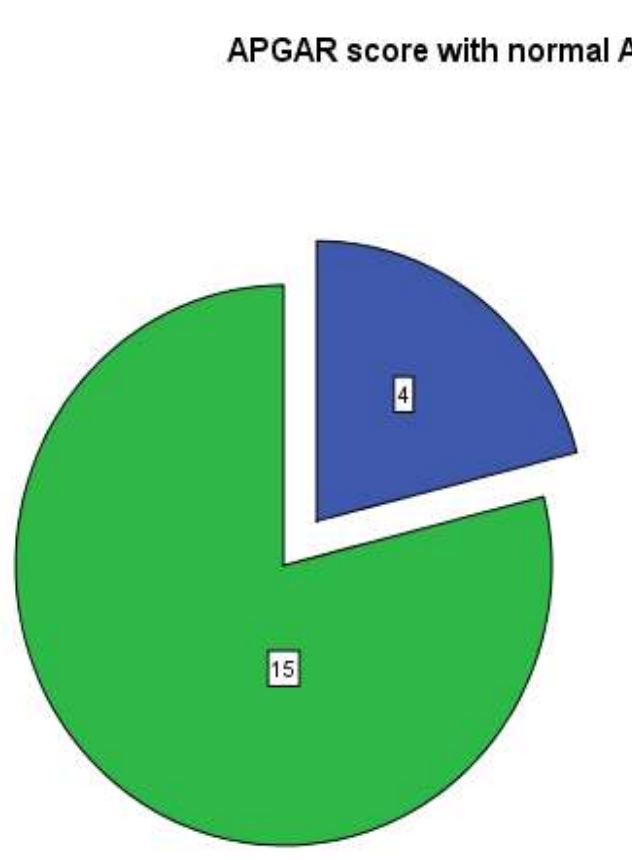

The present study shows that borderline AFI in an uncomplicated late preterm pregnancy was not found to increase the risk of adverse maternal and perinatal outcomes. There are few studies in the literature to evaluate borderline AFI and adverse perinatal outcomes. In a study by Soo Ran Chpoi, the author reported borderline AFI in uncomplicated term pregnancy was not associated with adverse perinatal outcomes (Choi, 2016). In another study by Nilgun Ozturk Turhan A total of 90 cases were identified as borderline amniotic fluid and 277 cases as normal AFI. A significant increased incidences of admission to neonatal intensive care unit, intrauterine growth restriction, meconium-stained amniotic fluid, intrapartum fetal distress in the group with borderline amniotic index $(P<0.05)$ was noticed (Gumus et al., 2007). In another study by Gokhan Acman, 30 pregnant women with an uncomplicated singleton pregnancy at a gestational age of $34+0-36+6$ weeks were included. Borderline oligohydramnios was defined as an amniotic fluid index (AFI) of 5.1-8 cm, which was measured using the four-quadrant technique. Adverse perinatal outcomes were compared between the borderline and normal AFI groups. Approximately 107 of the 430 pregnant women were borderline AFI, and 323 were normal AFI. The demographic and obstetric characteristics were similar in both groups. Cesarean delivery for non-reassuring fetal heart-rate testing, meconium-stained amniotic fluid, Apgar $5 \mathrm{~min}<7$, were not statistically different between the groups $(\mathrm{p}=.134, \mathrm{p}=.749, \mathrm{p}=0.858, \mathrm{p}=.703$, respectively) (Sahin et al., 2018).

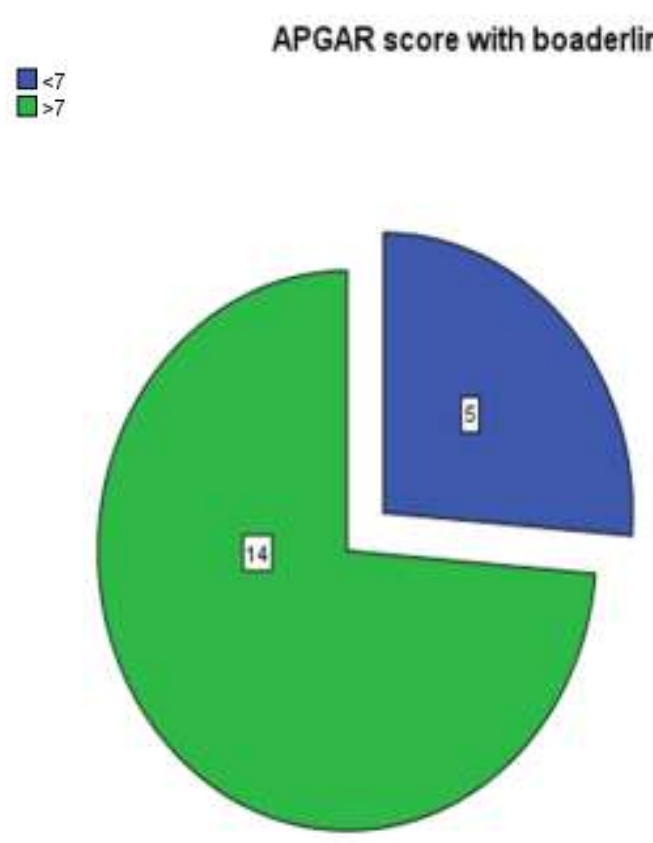

Fig. 1: Pie chart illustration of APGAR score as perinatal outcomes with normal and borderline AFI 
Informed Consent: Written information was obtained from the participants of this study

Financial Disclosure: The authors declared that this study received no financial support

Inclusion Criteria: All female patients at late preterm pregnancy with normal and boarder line oligohydramnios

Patients' consent: Written informed consents on the protocol were obtained from the patients to publish the data concerning this case

\section{Author's Contribution}

All the authors in the study designed the research plan, performed experimental works, collected the required data and analysed the data. All authors jointly prepared the manuscript, critically revised and finalized the manuscript.

\section{Conflict of Interest}

The authors declare that there is no conflict of interest with present publication.

\section{References}

Berchicci M, Tamburro G \& Comani S (2015) The intrahemispheric functional properties of the developing sensorimotor cortex are influenced by maturation. Frontiers in human neuroscience 9: 39. DOI: 10.1016/S0002-9378(16)32235-9

Berglund S, Pettersson H, Cnattingius S \& Grunewald C (2010) How often is a low Apgar score the result of substandard care during labour? BJOG: An International Journal of Obstetrics \& Gynaecology 117: 968-978. DOI: $\underline{10.1016 / 0002-9378(84) 90237-0}$

Chauhan SP, Sanderson M, Hendrix NW, Magann EF \& Devoe LD (1999) Perinatal outcome and amniotic fluid index in the antepartum and intrapartum periods: a meta-analysis. American journal of obstetrics and gynecology 181: 14731478. DOI: $10.1016 / \mathrm{S} 0002-9378(99) 70393-5$

Choi SR (2016) Borderline amniotic fluid index and perinatal outcomes in the uncomplicated term pregnancy. The Journal of Maternal-Fetal \& Neonatal Medicine 29: 457460. DOI: $\underline{10.7863 / j u m .2011 .30 .4 .523 ~}$

Gumus II, Koktener A \& Turhan NO (2007) Perinatal outcomes of pregnancies with borderline amniotic fluid index. Archives of gynecology and obstetrics 276: 17-19. DOI: 10.3389/fnhum.2015.00039

Hill LM, Breckle R, Wolfgram KR \& O'brien PC (1983) Oligohydramnios: ultrasonically detected incidence and subsequent fetal outcome. American journal of obstetrics and gynecology 147: 407-410. DOI: 10.1111/j.1471$\underline{0528.2010 .02565 . \mathrm{x}}$

Iliodromiti S, Mackay DF, Smith GC, Pell JP \& Nelson SM (2014) Apgar score and the risk of cause-specific infant mortality: a population-based cohort study. The Lancet 384: 17491755. DOI: 10.1016/S0140-6736(14)61135-1

Magann EF, Chauhan SP, Hitt WC, Dubil EA \& Morrison JC (2011) Borderline or marginal amniotic fluid index and peripartum outcomes: a review of the literature. Journal of Ultrasound in Medicine 30: 523-528. DOI: 10.7863/jum.2011.30.4.523

Mercer LJ, Brown LG, Petres RE \& Messer RH (1984) A survey of pregnancies complicated by decreased amniotic fluid. American journal of obstetrics and gynecology 149: 355361. DOI: $10.3109 / 14767058.2015 .1004051$

Sahin E, Madendag Y, Tayyar AT, Sahin ME, Col Madendag I, Acmaz G, Unsal D \& Senol V (2018) Perinatal outcomes in uncomplicated late preterm pregnancies with borderline oligohydramnios. The Journal of Maternal-Fetal \& Neonatal Medicine, 31: 3085-3088. DOI: $\underline{10.1080 / 14767058.2017 .1364722}$ 